\title{
LA BLASFEMIA DEL REY SABIO: VICISITUDES DE UNA LEYENDA (NUEVAS HIPÓTESIS RESPECTO A LA DATACIÓN Y LA POSICIÓN RELATIVA DEL TEXTO PORTUGUÉS)
}

\author{
THE LEARNED KING'S BLASPHEMY: VICISSITUDES OF A \\ LEGEND (NEW HYPOTHESIS REGARDING THE DATING AND \\ THE RELATIVE POSITION OF THE PORTUGUESE TEXT)
}

\author{
ISABEL DE BARROS DIAS \\ Universidade Aberta \\ IELT-EISI - IEM (UNL-FCSH)
}

\begin{abstract}
Resumen: Este artículo cuestiona algunas ideas existentes sobre la leyenda de la blasfemia de Alfonso X, en particular lo relativo a su presencia en la crónica portuguesa de 1344, redactada por Pedro Afonso de Barcelos, biznieto del rey Sabio. La puesta en valor de un dato menos considerado, la ausencia de este relato en el manuscrito truncado que transmite la primera redacción de la obra del conde portugués, estimula el planteamiento de una nueva hipótesis, basada en reflexiones no solo textuales, sino también contextuales (tanto de índole personal como política).
\end{abstract}

Palabras clave: Alfonso X; leyenda; blasfemia; Pedro Afonso de Barcelos; Crónica de 1344.

\begin{abstract}
This article questions some existing ideas about the legend of the blasphemy of Alfonso X, especially concerning this narrative's presence in the Portuguese chronicle of 1344 , written by Pedro Afonso de Barcelos, great-grandson of the Learned King. The consideration of a often overlooked fact, the absence of this story in the truncated manuscript that conveys the first version of the Portuguese count's work, stimulates a new hypothesis, based on reflexions on not only on textual, but also on contextual issues (of both personal and political kind).
\end{abstract}

Keywords: Alfonso X; legend; blasphemy; Pedro Afonso of Barcelos; Chronicle of 1344 .

\section{SUMARIO}

1. Estado de la cuestión.- 2. Algunas hipótesis respecto a la datación y la posición relativa del testimonio portugués.- 3 . Bibliografía citada. 


\section{ESTADO DE LA CUESTIÓN}

El episodio de la blasfemia del rey Sabio no pertenece al conjunto de los temas que más ha llamado la atención de los estudiosos que, desde varios puntos de vista, se han interesado por la historiografía postalfonsí. Por eso, la bibliografía existente respecto de esta leyenda es limitada, a pesar de que se trate de un relato muy curioso y que ha estimulado hipótesis bastante interesantes.

Entre los autores que más recientemente han examinado el episodio, destacan tres nombres, por el interés e importancia de sus aportaciones: Leonardo Funes ${ }^{1}$ y Georges Martin ${ }^{2}$, por sus estudios sobre las funciones ideológicas y políticas que ha tenido la leyenda, y Amaia Arizaleta, que ha considerado el perfil de soberano existente en el relato ${ }^{3}$.

También hemos estudiado esta leyenda, en un primer momento ${ }^{4}$ como parte de una línea que consideraba negativamente la memoria del rey Sabio. Años después ${ }^{5}$, nuestras reflexiones han incidido sobre los antecedentes de este relato. En este artículo, hemos recordado dos pasajes traídos a colación en las Memorias antiguas de Cardeña, publicadas en 1721 por Francisco de

${ }^{1}$ Funes 1993, 1994, donde el autor hace un minucioso análisis de las variantes de esta leyenda, de las razones que han podido motivar sus cambios y, en estrecha relación, de los varios fines a que ha servido en distintos ambientes políticos y culturales. De hecho, la leyenda habría servido tanto para legitimar la rebelión del infante Sancho contra Alfonso X, como, cien años más tarde, para justificar el final de su linaje, considerado maldito, y su sustitución por los Trastámara. Los marcos que Funes establece son los siguientes: 1) surgimiento de la leyenda en el entorno de los rebeldes que rodeaban al infante Sancho para justificar sus acciones contra Alfonso X. Esto es señalado también por Catalán 1953, p. 65; Ballesteros-Beretta 1963, p. 209; Craddock 1986, p. 207; Ruiz 1989, p. 82; 2) la leyenda se emplea para impugnar la dinastía reinante en Castilla y consecuentemente sus derechos sucesorios (linaje maldito e ilegítimo) -véase el Libro de las Armas de don Juan Manuel-; 3) la leyenda sirve para justificar el fin violento del linaje de Sancho IV -al final de cuatro generaciones malditas (Sancho IV; Fernando IV, el Emplazado, también maldito; Alfonso XI y Pedro I) - y la llegada de Enrique II de Trastámara al poder, en el contexto de la guerra civil entre Pedro I y su medio hermano Enrique II de Trastámara. La misma opinión ha sido sostenida por Entwistle 1925, p. 176; Catalán 1953, p. 65; Craddock 1986, p. 207.

${ }^{2}$ Martin 1994 -en este artículo el autor reflexiona sobre la maldición de Alfonso X a su hijo Sancho y la subsiguiente construcción literaria e ideológica, que acabó por provocar el final de su dinastía, contexto en el cual el papel de la leyenda de la blasfemia tiene un lugar destacado. En este artículo, el autor expone razonamientos de gran interés sobre la participación de don Juan Manuel y de don Pedro Afonso en el desarrollo y difusión de esta construcción ideológica-

${ }^{3}$ Arizaleta 2004 -en este artículo Arizaleta estudia las leyendas de la blasfemia del rey Sabio y de la judía de Toledo. Considera los linajes interesados en la difusión de las dos leyendas y traza el modelo de monarca que estos relatos propagan, destacando el motivo de la soberbia del rey y su castigo-.

${ }^{4}$ Dias 2003, II Parte, 2.5 .

${ }^{5}$ Dias 2012. 


\section{Berganza $^{6} \mathrm{y}$, además, hemos subrayado la posible importancia de otro testimo- nio, un pasaje existente en la biografía de Alfonso X, por Juan Gil de Zamora, que fue publicada en 1884 por Fidel Fita ${ }^{7}$. Hemos sugerido que este episodio}

\footnotetext{
${ }^{6}$ Ballesteros-Beretta 1963, pp. 209-211 ha señalado la posibilidad de una relación con un suceso ocurrido en Segovia e incluido en estas Memorias, donde podemos leer: "Era de MCCXCVI años fundiòse el Palacio de Segovia con El Rey D. Alfonso, e con muchos de sus ricos omes, e con Obispos: e murió y ... e Maestre Martin de Talavera, Dean de Burgos: fueron feridos otros muchos Obispos, e ricos omes, e fincò el Rey sano, e esto fuè el dia de Sant Vitores, a ora de yantar, cinco dias por andar del mes de Agosto". Pero atendiendo a todas las noticias, podemos encontrar otra, quizás más cercana a la leyenda, y que es la siguiente: "Era de MCCXCII. años, en dia de Sant Lucas entró en Burgos Don Adoart, è prisò por muger à la hermana del Rey Don Alfonso, fija del Rey Don Ferrando, el que prisò Sevilla. Vino vn fuego del Cielo, è cayo antel Rey en la Glera de Burgos, e fizo gran sueno." (Berganza 1721 -los dos pasajes están en la p. 589-). Los pasajes fueron reeditados por Flóres 1799, pp. 374 y 375 -el Cronicón fue fechado en 1327 por Menéndez Pidal 1918-. Para una visión general sobre Anales y Cronicones ibéricos medievales, véase Bautista 2009, que incluye el Cronicón (o Anales) de Cardeña en la vertiente más antigua de la tradición analística peninsular (p. 147). Sin embargo, parece que hay otras tradiciones que hablan también de la caída de un rayo, pero en Segovia -véase la cita reportada por Ruiz de Obregón 1915-: "Finalmente, un notable historiador, no tan conocido como acaso debiera serlo, Colmenares, en su Historia de Segovia, hace el relato siguiendo á Almela, y añade: «Muchas historias nuestras dexan de escrivir este caso como otros muchos. Pero escritores advertidos le escribieron para confusión de sabios presumidos. Frai Alonso de Espina, en su Fortalicio de la Fe, aunque diferencia el modo: Vna Historia mui antigua, manuscrita en papel y letra de aquel tiempo, que tenemos en nuestra librería, refiere como dexamos escrito: Don Rodrigo Sánchez, Obispo de Palencia en su Historia Latina de España: señalando que fué antes que partiesse á coronarse Emperador: El Autor del Valerio de Historias Escolásticas, Diego Rodríguez de Almela, Arcipreste de Val de Santiváñez, que publicó Fernán Pérez de Guzmán: El Maestro Pedro Sánchez de Acre, en su Historia Moral y Filosófica: Gerónimo de Zurita, en sus Anales de Aragón: Juan de Mariana, en su Historia de España: y Pisa, en la de Toledo: y Juan Cuspiniano, en sus Césares y, sobre todo, la tradición constante de nuestra ciudad y señales del suceso: estas son las roturas que hizo el rayo y se ve hoy en la parte interior de la bóbeda, que es de fortísima cantería, en la sala nombrada del Pabellón, por semejarle su fábrica, y se mostrava por la parte de fuera en la media naranja hasta que se empiçarró por los años 1590, y aunque no emos visto autor que señale el año del suceso, le ponemos en éste de 1262 , porque todos escriven que desde este caso descaeció la grandeza del Rey, y en su buen govierno, sucediéndole todo mal; y su Chronica refiere que estando en nuestra Ciudad en este mismo año le llegaron avisos de tropel»" (pp. 431-432).

${ }^{7}$ En este texto podemos leer lo siguiente: " 23 . Aldefonsum etiam prefatum Dominus altissimus et eternus a multis periculis liberavit. Nam semel, cum esset apud Secobiam cum suis secretariis secreta consilia sua tractans, solarium corruit cum eisdem; et aliis dirutis et destructis, evasit ipse incolumis et illesus. Apud Secobiam similiter cum in sero de civitate tres in ipsum sagitas emisissent ut ipsum vita et regno privarent, sagite in partem aliam voluntate doifica declinarunt, et in quodam lignum loco superpositum impegerunt, Regis interitum declinantes. A quibus vero vel a quo sagite fuerunt misse, et cujus seu quorum consilio, varie decantatur; et sanius judicio subticere quam super facto tam enormi aliquid sorsptitare. Cum etiam idem Rex esset apud Toletum, fulgur terrificum, de nubibus acelerans, locum ubi erat Rex cepit quasi exploratorie circuire; et hinc inde percutiens prosilit quasi reverentiam faciens ipsi Regi. Multa quoque alia circa ipsa pericula contigerunt a quibus ipsum liberavit misericorditer Deus altissimus et eternus veniam sibi dando, ut ob ista oculos ad celum levaret et recognosceret quod in manu Domini est opera cujuslibet creature, et ad illum locum dirigitur quo voluntas dirigitur gubernantis." (Fita 1884, pp. 322-323). Es interesante verificar que dos de los tres sucesos referidos (la caída de un techo, tres flechas echadas contra el rey y un rayo desgobernado) son compatibles con lo que es reportado en las Memorias antiguas de Cardeña. Pero aquí los
} 
podría considerarse como un testimonio de una primera interpretación respecto de la caída de un rayo y por eso estaría en el origen de la leyenda de la blasfemia. Pero este texto transmite una interpretación del suceso totalmente distinta de las siguientes, o sea, no como motivo de crítica contra Alfonso X o sus descendientes, sino buscando nítidamente la alabanza del rey Sabio como protegido por Dios.

Los estudios que hemos cotejado sobre el tema de la leyenda de la blasfemia del rey Sabio consideran que el texto de la Crónica de 1344 sería la primera narración escrita de esta leyenda en cuanto tal, y obra de Pedro Afonso, conde de Barcelos, hijo natural del rey Dinis de Portugal, y bisnieto de Alfonso $\mathrm{X}^{8}$. Pero cuando leemos el relato portugués existente ${ }^{9}$, lo encontramos muy lejos

sucesos son interpretados a modo de ensalzamiento del rey, subrayando la protección que Dios le dispensaba. Este texto y episodio son señalados y contrastados con la versión portuguesa de la leyenda por Linehan 1993, pp. 457-58, pero este autor no discute posibles conexiones entre los dos textos.

${ }^{8}$ Catalán 1953, p. 64 dice que la primera redacción de la Visión se halla en la Crónica de 1344; Ruiz 1989, p. 80 también acepta esta idea. Lo mismo hace Funes, que considera la leyenda "obra plena del conde de Barcellos" (1993, p. 62 -también en la p. 57-) y Martin 1994, pp. 168-170, que considera que don Pedro Afonso es el primer historiador en integrar la leyenda. Craddock 1986, p. 207 defiende que la leyenda no sería invención de don Pedro Afonso, pero que ha sido él el responsable de su integración en la historia. Ramos Nogales considera que es en la crónica atribuida al conde Pedro de Barcelos donde aparece "La primera documentación conocida de la leyenda" (Ramos 1992, p. 189). González Jiménez dice que el texto portugués "de momento, puede ser considerado como la versión más antigua conocida de la leyenda" (González 1995,p. 464) y sugiere la existencia de una fuente castellana perdida (pp. 464 y 468).

${ }^{9}$ La leyenda aparece en la primera parte del relato de la vida de Fernando III, cuando se habla de la familia y descendencia de este rey (Cintra 1990, vol. IV, pp. 379-384). Para el comienzo de este reinado, el texto de la crónica portuguesa sigue la Crónica de Castilla, pero con interpolaciones que Cintra describe a partir de la p. CCLVI (Cintra 1951, vol. I). En líneas generales, esta versión cuenta lo siguiente:

Un día el príncipe Alfonso sirve vino muy apuestamente a sus padres y viéndolo así su madre da un gran suspiro y empieza a llorar. El rey Fernando le pregunta la razón de este comportamiento y la reina le cuenta un episodio de su juventud en el que una mujer griega, a quien su madre consultaba sobre muchas cosas, le había profetizado (entre otros hechos que, mientras tanto, ya habían tenido lugar) que su hijo mayor tendría muchas cualidades y sería muy poderoso y honrado durante mucho tiempo, pero al final sería desheredado de toda su tierra salvo de la ciudad donde moriría, y todo esto por causa de una frase de soberbia que habría de decir.

En una segunda escena, el rey Fernando III recibe quejas de que el infante Alfonso había tomado dinero destinado a los fronteros. El rey lamenta el hecho y cuenta las palabras de la reina, añadiendo que cree que la profecía se va a cumplir por lo que ve hacer a su hijo.

Descubrimos entonces cuáles fueron las palabras de Alfonso: que si hubiera estado con Dios o si hubiera sido su consejero cuando Él creó el mundo, algunas cosas, si Dios le hubiera hecho caso, habrían sido mejor hechas de lo que fueron.

Mientras tanto, Pero Martĩiz, un caballero que criara al infante Manuel, tuvo una visión de un hombre vestido de blanco que le dijo que el rey Alfonso iba a terminar mal si no se arrepentía de lo que había dicho públicamente en Sevilla. A instancias del infante, el caballero va a prevenir el rey, que insiste en su blasfemia.

Poco después, estando el rey en Segovia, un fraile menor tiene la misma visión y previene al rey, que se comporta de la misma manera. Esa noche sobreviene una tormenta y un rayo entra en la cámara y quema muchas cosas, incluso las tocas de la reina. El rey tiene mucho miedo y 
de los primeros testimonios que hemos identificado, en particular, del relato de Juan Gil de Zamora. De hecho, el texto de la biografía es el relato de un suceso seguido de interpretación, mientras que el episodio de la Crónica de 1344 es una narración estructurada y estilísticamente elaborada. Además, en el plano ideológico, el texto del zamorano busca ejemplificar la alianza entre el rey y Dios, mientras que en el relato portugués la lectura sobrenatural es sumamente negativa, pues muestra la soberbia, la rivalidad y la rebeldía del rey contra Dios.

El hiato que constatamos entre estos dos testimonios es un estímulo para investigar sobre lo que podría haber sucedido entre ellos. Es este el asunto del presente artículo: revisar lo que ha sido dicho sobre el tema y proponer una hipótesis alternativa.

Cintra, al editar la Crónica de 1344, cuando llega a este pasaje, dice en el aparato crítico: A partir de aqui, fonte desconhecida ${ }^{10}$, como en la cartografía antigua, al final del mundo conocido.

La crítica a la cual hemos tenido acceso y que hemos cotejado remedia el problema de la ausencia de una fuente escrita con la hipótesis de una circulación oral anterior ${ }^{11}$. El conde portugués habría tenido conocimiento de esta tradición y cuando redactó su versión de la historia peninsular, por alguna razón, decidió incorporar la anécdota en el relato de la vida de Fernando III, en el momento en el que se habla de su descendencia.

Algunos razonamientos desarrollados por la crítica muestran que don Pedro Afonso tuvo ocasión de conocer alguna leyenda que circulaba sobre su bisabuelo. Se cree habitualmente que el conde portugués habría tenido conocimiento de la obra de Alfonso X y contactado con los métodos historiográficos de su escuela durante su estancia más prolongada en Castilla (su exilio de 1317-1322), momento en el que habría frecuentado la corte de María de Moli$\mathrm{na}^{12}$. Don Pedro Afonso habría podido conocer la leyenda, fuera en ese periodo, fuera (con menor probabilidad) en sus otras estancias, en 1336 y $1340^{13}$.

se arrepiente de sus palabras. Llama al fraile y, mientras se confiesa, la tormenta se calma. En el día siguiente el rey hace confesión pública de su blasfemia y manda buscar el cuerpo de santa Bárbara, pero no lo logra.

${ }^{10}$ Cintra 1990, vol. IV, p. 379.

${ }^{11}$ Funes 1993 presenta la Crónica de 1344 como el primer testimonio de la leyenda (p. 57) que anteriormente habría circulado oralmente (pp. 56, 58, 69). Aun según este autor, la transición de la oralidad a la escritura habría ocurrido en los años 40 del siglo XIV (p. 67). Arizaleta 2004, p. 92 y también en 2009, p. 294, habla incluso de una leyenda oral que circularía desde el último tercio del siglo XIII. La circulación oral de la leyenda es referida también por González 1995, p. 471; 2004, p. 449.

${ }^{12}$ Véase Cintra 1951, vol. I, p. CLXXXIX.

${ }^{13}$ El conde estuvo desterrado cerca de cuatro años y medio en Castilla. Durante ese tiempo habría frecuentado la corte de la regente, María de Molina. Volvió a Portugal en torno a 1322, lo que significa que se habría marchado a mediados de 1317 (Cintra 1951, vol I, pp. CXLVI-CLI). Se marchó también a Castilla en 1336, cuando Afonso IV de Portugal declara la guerra al rey de 
Otras dos posibilidades de transmisión de la leyenda al conde de Barcelos han sido señaladas por Georges Martin ${ }^{14}$ : la coincidencia en la corte de Portugal con Constanza Manuel ${ }^{15}$, y la transmisión por vía de la familia de los Lara, de los cuales el conde sería allegado ${ }^{16}$.

Incluso se ha planteado la hipótesis de que don Pedro Afonso pudo haber conocido la leyenda de la blasfemia por don Juan Manuel ${ }^{17}$. Estas dos figuras han sido comparadas bastantes veces. Ambos compartían el gusto por las letras, un status elevado y defendían principios de gobierno y de organización social parecidos. Asimismo, los dos eran contemporáneos y la posibilidad de que hubieran coincidido en la corte castellana es grande ${ }^{18}$. Esta conexión es pertinente para la cuestión de la leyenda de la blasfemia del rey Sabio, porque tenemos una referencia al padre de don Juan Manuel en el texto portugués, pues el caballero que tiene la visión por primera vez es hũu cavaleiro de Panpigra, que avya nome Pero Martĩiz e criara o iffante dõ Manuel ${ }^{19}$, y él va a avisar al rey a instancias del infante (a quien cuenta primero lo sucedido). Además, en la obra de don Juan Manuel también hay referencias, aunque vagas, a sueños premonitorios asociados al rey Sabio:

Digo vos que a estos sobredichos oy que quando la reyna donna Beatriz mi abuela era en çinta de mio padre, que sonnara que por aquella criatura et por su linage avia a ser vengada la muerte de Ihesu Christo et ella dixo lo al rey don Ferando su marido. Et oy dezir que dixera el rey quel pareçia este suenno muy contrario del que ella sonnara quando estaua en çinta del rey don Alfonso su fijo que fue despues rey de Castiella, padre del rey don Sancho ${ }^{20}$.

Castilla porque este retenía a la esposa de su hijo, Constanza Manuel, y después, en 1340, en el marco del apoyo militar de Portugal a Alfonso XI, en la batalla del Salado.

${ }^{14}$ Martin 1994, p. 176.

${ }^{15}$ Lo que no sería imposible, a pesar de que durante los años en que Constanza Manuel había sido reina de Portugal (entre 1339 y 1345) no hay noticia de que don Pedro Afonso frecuentara la corte de su medio hermano Afonso IV: "Não temos notícia nesta época da sua permanência na corte de Afonso IV, o que não quer dizer que não a visitasse uma que outra vez" (Cintra 1951 , vol. I, p. CLXIX). Cintra considera los años entre 1325 y 1354 como la tercera fase de la vida del conde: después de una primera fase en que vivió sobre todo en la corte de su padre, el rey Dinis, siguió el exilio y, por fin, una fase más calmada, en sus dominios, en la Beira (Cintra 1951, vol. I, p. CLXIX).

${ }^{16}$ Sobre la amistad de don Pedro Afonso con Juan Núñez de Lara véase Cintra 1951, vol. I, pp. CXLVII-CXLIX.

${ }^{17}$ Esta posibilidad es sugerida por Ruiz, refiriéndose a Catalán: "La segunda posibilidad fue propuesta recientemente por Diego Catalán: puede ser que fue el mismo don Juan Manuel el que se lo contó al conde de Barcelos en alguna ocasión" (Ruiz 1989, p. 83). La posibilidad también es considerada por Martin 1994,pp. 175-176.

${ }^{18}$ Véase Cintra 1951, vol. I, p. CL.

${ }^{19}$ Cintra 1990, vol. IV, p. 382.

${ }^{20}$ Juan Manuel 2005, p. 5. 
Esto ocurre en el Libro de las Armas, poco anterior a 1344 (datado en torno a 1337-1342), donde también se relata una confesión del rey Sancho IV en su lecho de muerte y constan varias consideraciones sobre maldiciones:

Ca el sancto rey don Ferando mio abuelo non dio su bendiçion al rey mio padre sinon guardando él condiçiones çiertas que él dixo et él non guardó ninguna dellas et por esso non ovo la su bendiçion. Otrosi la reyna mi madre cuydó que non ovo la bendiçion de su padre, ca la desamaua mucho por la sospecha que ovo della de la muerte de la jnfanta donna Constança su hermana. Et asi mio padre nin mi madre non avian bendicion de los suyos nin la pueden dar a mí et yo fiz tales fechos porque mereçí et oue la su maldicion et por ende lo que yo non he non lo puedo dar a uos nin a ninguno ${ }^{21}$.

En verdad, estos apuntes son alusiones bastante vagas. Además las diferencias con relación al texto de la Crónica de 1344 son grandes. El tema de los sueños premonitorios podría ser compatible con el de las profecías, pero lo que este texto subraya y desarrolla es sobre todo la cuestión de las bendiciones y de las maldiciones paternas.

¿Pudieron existir dos leyendas en tiempos de don Juan Manuel y de don Pedro Afonso? ¿O cada uno de ellos pudo haber reescrito una misma base legendaria oral de diferentes modos por razones distintas ${ }^{22}$ ? Pero si don Juan Manuel conociera una leyenda más dura contra Alfonso X, ¿por qué razón no la habría referido? ¿Por admiración intelectual ${ }^{23}$ ? Es cierto que don Juan Manuel admiraba la obra de Alfonso X, pues lo había declarado ${ }^{24}$. Pero en el Libro de

${ }^{21}$ Ibidem, p. 20.

${ }^{22}$ Como ha sido sugerido por Funes 1993, p. 69.

${ }^{23}$ Catalán considera esta posibilidad cuando dice, en nota: "Creo imposible, por otra parte, que semejante leyenda, nacida de la incomprensión de la figura del rey Sabio y su labor científica, fuese creada por don Juan Manuel, gran admirador de la obra de Alfonso X." (Catalán 1953, p. 65n). Entwistle 1925, pp. 178-179 sugiere la conexión con el linaje del infante Manuel y, sobre todo, con don Juan Manuel. Ruiz 1989, pp. 82-83 considera la posibilidad de que "la propagación oral de dicha leyenda pudo haber comenzado con el infante don Manuel". Esta opinión es compartida por Funes 1993, p. 69, y por Arizaleta 2004, pp. 92-93; 2009, p. 294.

${ }^{24} \mathrm{La}$ admiración de don Juan Manuel por Alfonso X es evidente en este pasaje de la Crónica Abreviada: "E esto por muchas razones: lo vno, por el muy grant entendimiento que Dios le dio; lo al, por el grant talante que auie de fazer nobles cosas e aprouechosas; lo al, que auia en su corte muchos maestros de las ciencias e de los saberes a los quales el fazia mucho bien, e por leuar adelante el saber e por noblescer sus regnos. Ca fallamos que en todas las ciencias fizo muchos libros e todos muy buenos. E lo al, por que auia muy grant espacio para estudiar en las materias de que queria conponer algunos libros. Ca morava en algunos logares vn anno e dos e mas, e avn, segunt dizen los que viuian a la su merced, que fablauan con el los que querian e quando el queria, e ansi auia espacio de estudiar en lo quel queria fazer para si mismo, e avn para veer e esterminar las cosas de los saberes quel mandaua ordenar a los maestros e a los sabios que traya para esto en su corte.” (Juan Manuel 1983, pp. 575-576). 
las Armas los propósitos de carácter personal y políticos son preponderantes, como ha demostrado Ruiz ${ }^{25}$. En este contexto, a pesar de que la omisión pueda ser una estrategia muy sutil, tendría sentido que el autor hiciera una alusión más explícita a una leyenda que fuera en la línea de sus empresas, ensalzando a su padre y criticando a Alfonso X, para que no quedaran dudas sobre el asunto al que se refería ${ }^{26}$. Además, lo que se lee en el Libro de las Armas, a pesar de que minusvalora al rey Sabio, incide sobre todo sobre Sancho IV.

Otra línea argumentativa importante es la que concierne los motivos que han podido estimular a don Pedro Afonso a integrar este suceso en su historia. La Crónica de 1344 presenta una ideología distinta a la defendida por los textos alfonsíes, pero a pesar de elegir una perspectiva opuesta a la del rey Sabio, el conde de Barcelos usa extensamente materiales alfonsíes y se inserta de buen grado en esta tradición historiográfica. De hecho, podemos identificar en la obra portuguesa, en sus dos versiones, los trazos de la admiración por la obra del rey Sabio, en virtud de su utilización como fuente, lo que implica su consideración como Auctoritas.

Por otro lado, sabemos también que don Pedro Afonso no se excusó de divulgar historias poco convenientes sobre reyes pues lo hace a propósito del primer rey de Portugal, en su Livro de Linhagens ${ }^{27}$. Pero, en el texto

\footnotetext{
${ }^{25}$ Ruiz 1989.

${ }^{26}$ Martin ha señalado, muy apropiadamente: "car, en vérité, c'est ce qui atteint Sanche IV qui fait valoir les La Cerda et ce qui atteint Alphonse X qui fait valoir les Manuel" (Martin 1994, p. 172). De hecho, como subraya Ruiz 1989, p. 83: "fue el infante don Manuel el que capitaneó a los rebeldes que apoyaran al infante don Sancho en contra de su padre el rey Sabio.". De esta manera, la leyenda contra Alfonso X justificaría las acciones del padre de don Juan Manuel (tal como las del rey Dinis de Portugal). Bastante interesante para esta cuestión es también el artículo de Ramos 1992, pues el autor demuestra que don Juan Manuel, bajo el argumento que reporta en el Libro de las Armas informaciones que había escuchado, toma motivos de las tradiciones bíblica y literaria atribuyéndolos a personajes históricos concretos (incluso incurriendo en incongruencias, señaladas en este artículo). Ramos Nogales integra la historia de las premoniciones de la reina Beatriz en esta línea estratégica que tiene como finalidad última ensalzar la preeminencia del linaje de don Juan Manuel por encima de todos los otros, incluso del linaje del soberano. En este sentido, las premoniciones podrían haber sido forjadas por el autor a partir de otros relatos que conocería (véase Ramos 1992, pp. 186-188). La imprecisión cuanto al sueño premonitorio relativo a Alfonso X, del cual solo su carácter negativo es subrayado, permite su asociación a la leyenda de la blasfemia (Ramos 1992, p. 189). La estrategia de omitir una información, quizás porque es tan negativa que el autor no se atreve a repetirla, sería bastante eficaz y minusvaloraría a Alfonso X. En el caso en que la alusión estimulara automáticamente una asociación a la leyenda de la blasfemia, esta debería ser en ese momento ya suficientemente conocida como para no necesitar de una referencia detallada (y nos preguntamos ¿lo seria?). Por otro lado, puede también admitirse que la alusión existente en el Libro de las Armas no sea sino una estrategia más difusa destinada a lanzar la sospecha y a estimular la imaginación de todos cuantos conociesen este Libro.

${ }^{27}$ Véase Mattoso 1992, pp. 37-38. Los relatos que ponen en ridículo a Afonso Henriques tendrían origen en el marco de la alta nobleza señorial del norte de Portugal. Estos sucesos han sido integrados en los Livros de Linhagens, incluso en el de Pedro Afonso, conde de Barcelos.
} 
existente de la primera versión de la Crónica de 1344, y en la mayor parte de la segunda redacción, no hay otros casos de animosidad directa contra el rey $\mathrm{Sabio}^{28}$.

Todavía en este dominio sobre las razones posibles, Martin ha señalado algunos argumentos importantes, a pesar de que, como el propio autor admite, hay algunas contradicciones:

- el hecho de que el rey Dinis de Portugal, padre de don Pedro Afonso y nieto de Alfonso $\mathrm{X}$, hubiera apoyado la rebelión de Sancho contra su padre y que una leyenda contra Alfonso X justificaría las acciones de su padre ${ }^{29}$;

- las buenas relaciones del conde de Barcelos con la familia de los Lara, defensora de los derechos de los infantes de la Cerda al poder y aliados de don Juan Manuel y de los reyes de Francia contra la descendencia de Sancho IV $^{30}$;

- como señal contraria a este último argumento, las buenas relaciones que don Pedro Afonso habría tenido con el rey Alfonso $\mathrm{XI}^{31}$, puesto que fue acogido en la corte de la abuela y regente del monarca, María de Molina, y en uno de sus desplazamientos a Castilla estuvo en el contingente de ayuda a este soberano en la batalla del Salado (1340).

\footnotetext{
${ }^{28}$ Excepto en una continuación de esta crónica, existente en el ms. de París, fechado en torno a 1460, y que hemos comentado en Dias 2012. En este pasaje, Alfonso X es presentado como un astrólogo, un brujo que se ocupa de experiencias sospechosas, e incluso peligrosas. Este detalle será un añadido tardío centrado en la crítica contra el paradigma del rey demasiado interesado en la búsqueda de conocimientos vedados. Sobre este tema, al que se asocia el topos de la soberbia castigada, y su aplicación a Alfonso X, véase Arizaleta 2004. El pasaje al que nos referimos y otros dos son comentados también por González 2004, pp. 454-455.

${ }^{29}$ Martin 1994, p. 176.

${ }^{30}$ Véase Martin 1994, pp. 171-172 y 176. A pesar de estas buenas relaciones, don Pedro Afonso habría relatado en su crónica el episodio de la sentencia del rey Dinis en favor de Fernando IV, defendiendo su soberanía sobre Castilla, contra las pretensiones del infante Alfonso de la Cerda: "A esta sazom andava fora da terra muy pobremẽte dõ Affonso, filho do iffante dõ Fernando Guedelha, por que se chamava rey de Castella, dizendo que era rey de dereito. Fallou el rey dom Denis cõ elle e fezelhe leixar o nome e voz de rey de Castella e o pendom e as armas que tragia e fez a el rey que lhe desse villas e castellos e muy grandes herdades ẽ Castella e outrossi lhe fez dar muy grande cõtia en dinheiros." (Cintra 1990, vol. IV, p. 250 - cap. DCCXXII). Este suceso es referido en el relato de la embajada del rey Dinis a Aragón como árbitro de las disputas entre Fernando IV de Castilla y Jaime II de Aragón, donde, además de arreglar esta discrepancia, el rey de Portugal es también llamado a establecer un acuerdo entre el rey de Castilla y el infante Alfonso de la Cerda. El relato se sitúa después del final (truncado) del manuscrito que contiene la primera versión de la Crónica de 1344. Pero el relato de la embajada ha sido considerado obra de don Pedro Afonso debido al carácter vívido y personal del texto, consecuencia de que el conde había sido testigo directo de estos sucesos. Este episodio ha sido considerado por Craddock en el marco de las disputas entre linajes (Craddock 1986, pp. 203-204).

${ }^{31}$ Véase Martin 1994, p. 176.
} 


\section{ALGUNAS HIPÓTESIS RESPECTO A LA DATACIÓN Y LA POSICIÓN RELATIVA DEL TESTIMONIO PORTUGUÉS}

Estas varias hipótesis que hemos recordado reflexionan sobre la posibilidad de que el conde don Pedro Afonso pudo conocer la leyenda de la blasfemia de Alfonso X y los motivos que lo pudieron estimular a integrar ese relato en su historia. Pese a la gran estructuración y la lógica inherente a estos razonamientos, hay un dato anterior que quizás aún no ha sido valorado convenientemente, pues no aparece en la bibliografía que hemos consultado. Se trata de que no tenemos evidencias textuales de la presencia de la leyenda en cuestión en la primera versión de la Crónica de 1344. El manuscrito más completo de esta versión termina truncado bastante antes de llegar a la historia de Fernando III ${ }^{32}$. Cintra, cuando decide editar la segunda versión de la crónica, considera que hay un alto grado de probabilidad de que lo que se encuentra en la segunda versión estuviera también en la primera ${ }^{33}$. Esto, en verdad, ocurre en abundantes fragmentos de la historia posterior al inicio de la Reconquista cristiana de la península. Pero también es cierto que hay diferencias entre las dos versiones y que estas, muchas veces, son significativas. Por esta razón, y salvo si se descubre un nuevo testimonio de la primera versión de la Crónica de 1344 que contenga este episodio, no podemos saber con seguridad si la leyenda de la blasfemia integraba, de hecho, esta versión y cómo sería esta, en el caso de que la integrara ${ }^{34}$.

Los estudios existentes sobre la leyenda de la blasfemia no se han dedicado a cuestionar la autoría del pasaje. La han aceptado, aun cuando son conscientes de que los testimonios existentes son posteriores a 1344 (caso de Arizaleta ${ }^{35}$ ). Es verdad que la crítica ha demostrado que el conde portugués tuvo la oportunidad de conocer alguna posible leyenda. Aunque los motivos que pudieran llevar a don Pedro Afonso a integrar este relato en su historia no sean tan claros, nada objeta a que no existiera en la primera redacción de la Crónica de 1344 una versión de la leyenda que aquí nos ocupa. En particular

\footnotetext{
${ }^{32}$ El ms. 2656 de la Biblioteca Universitaria de Salamanca es el testimonio más completo de la primera redacción de la Crónica de 1344 (que existe solo en traducción castellana). Desafortunadamente, este manuscrito termina abruptamente, truncado, en el reinado de Alfonso VII de Castilla y León, justo antes del momento en que empezaría la historia de los reyes de Portugal.

${ }^{33}$ Cintra 1951, vol. I, p. CDXCIII.

${ }^{34}$ Recientemente en el coloquio A Crónica de 1344 e a historiografia pós-alfonsina (Universidade Porto, 9-10 julio 2015) Ana Sofia Laranjinha planteó la hipótesis de que Lope García de Salazar podría conocer y haber utilizado la versión primitiva de la Crónica de 1344 cuando escribió el relato de la profecía y maldición de Alfonso X en sus Bienandanças e Fortunas. Como esta es una posibilidad que necesita ser comprobada, el asunto será sin duda debatido en trabajos futuros de la autora.

${ }^{35}$ Arizaleta 2004, p. 81.
} 
el interesante detalle del enlace de la leyenda con el apunte sobre las quejas a Fernando III sobre el dinero quitado por su hijo Alfonso, destinado a los guardianes de las fronteras, está bastante en la línea de la defensa de los derechos señoriales a los cuales el conde sería sensible ${ }^{36}$. Pero quizás ya no se pueda decir lo mismo, por ejemplo, de la elaboración retórica del pasaje.

De hecho, la inexistencia de una prueba textual estimula el planteamiento de preguntas y que se consideren posibilidades alternativas a la que hasta ahora ha sido elegida. En concreto, consideramos que debemos cuestionarnos si el texto, tal como lo leemos en la segunda redacción de la Crónica de 1344 , no estaría más encuadrado en las características y en el contexto de esta versión. Es esta la reflexión que será desarrollada enseguida. Dos líneas serán aquí consideradas: una contextual (y que va a incidir, tanto en argumentos de índole personal/emotiva, como en cuestiones de tipo político/ideológico) y otra de carácter textual.

Para la primera vertiente, dos argumentos de índole personal/emotiva podrán ser considerados como posibles disuasivos a que Pedro Afonso de Barcelos integrara una leyenda tan violenta contra el rey Sabio como la que podemos leer en el testimonio existente. Por un lado, la admiración intelectual (ya referida) que don Pedro Afonso sentiría por su antepasado ${ }^{37}$ y, por otro

36 "E el rey guardou sempre esta puridade que nunca o disse a nehũu ataa o tempo que teve cercada Sevilha que, estando na tenda de dom Rodrigo Affonso, cujo hospede era esse dya, chegou a elle hũu escudeiro de dom Nuno e disselhe da sua parte como os dinheiros que lhe mandara dar en Castella pera elle e pera os que estavam con elle por fronteiros en Geen que lhos tomara o iffante dõ Afonso, seu filho, e ainda outros dinheiros que viinham pera elle. E ainda o escudeiro non acabava de fallar esto a el rey quando chegou dom Nuno e querelousse a el rey daquelo meesmo per ante dom Rodrigo Afonso. E elle apartousse com elles a fallar e, contoulhes chorando todallas cousas que lhe a raynha dissera, segundo já avedes ouvido. E como, per aquela palavra que avya de dizer contra Deus, avya de seer deserdado do reyno, por que lhe farya mayor pesar que nũca lhe outro homen fezera desque prendera morte na cruz ataa entom. E que esto parecia muy bem seer verdade pelas obras que el fazia contra elle e contra aqueles que estavom en serviço de Deus." (Cintra 1990, vol. IV, pp. 381-382). Siendo el "Dom Nuno" al cual el texto se refiere Nuño González de Lara, padre de Juan Núñez de Lara, esta conexión podría constituir un argumento en favor de la posibilidad de que don Pedro Afonso hubiera conocido la leyenda por la familia de los Lara, como ha sugerido Martin 1994, p. 174. Señalamos además que una memoria similar (aquí es el infante Sancho quien avisa a Alfonso X de las quejas generales de los pueblos contra las malas acciones del rey) aparece en una crónica de Silos a la cual nos referiremos más adelante: "El infante don Sancho auido su acuerdo embiogelo mostrar al rey su padre e pedirle merced que non despechasse tanto los pueblos, que se armaria toda la tierra. El rey don Alfonso no lo touo en nada," (Lomax 1976, p. 333). También es curiosa la coincidencia, en el ms. 431 de la Biblioteca Nacional, de la leyenda / visión con una colección de hazañas de temáticas relacionadas sobre todo con los derechos de los hidalgos (Suárez 1942-1943). Sobre este ms., véase la nota 50.

${ }^{37}$ Podemos recordar que la admiración intelectual es la razón que ha llevado a Diego Catalán a alejar la posibilidad de que fuera don Juan Manuel el autor de la leyenda de la blasfemia -véase la cita en la nota 23-. Al contrario, González 2004, pp. 449, 451, 452 sugiere una "antipatía personal por Alfonso X" (p. 449), pero solamente a causa de la leyenda de la blasfemia (que considera obra de don Pedro Afonso) y no aporta otros datos que justificaran este sentimiento. 
lado, siendo el conde de Barcelos un hombre preocupado con la manutención de la solidaridad familiar ${ }^{38}$, ¿no sería un poco incongruente que divulgara una historia que denigrara tanto la memoria de su bisabuelo?

Por lo que respecta a la vertiente política e ideológica, podemos recordar los argumentos señalados por Martin ${ }^{39}$, sobre los motivos que habrían incitado a que el conde portugués integrara la leyenda de la blasfemia en su historia y la ambivalencia de estos motivos. Al contrario, el contexto político e ideológico del momento en que se habría redactado la segunda versión de la crónica portuguesa es bastante claro. Esta versión pudo haber sido compuesta ya en los años 80 del siglo XIV ${ }^{40}$. En este periodo han ocurrido acontecimientos que justifican ampliamente la aceptación e integración de una leyenda contraria a los reyes castellanos, especialmente las luchas por la independencia portuguesa contra Castilla, y el inicio de la segunda dinastía portuguesa.

Este contexto también puede justificar la omisión de la parte de la leyenda que se refiere a la maldición de los reyes castellanos hasta la cuarta generación, a pesar de que la segunda redacción de la Crónica de 1344 integre interpolaciones favorables a los derechos de Blanca -en oposición a los de Berenguela- al trono castellano que, por lo general, son articulados con el tema de los dos linajes enfrentados y luego con la leyenda de la blasfemia ${ }^{41}$.

\footnotetext{
${ }^{38}$ Como se ha planteado en el prólogo del Livro de Linhagens: "E por que nem ũa amizade nom pode ser tam pura segundo natura come daqueles que descendem de ũu sangue, porque estes movem-se mais ligeiro aas cousas per que a amizade se mantem, houve de declarar este livro per titolos e per alegações que cada ũu fidalgo de ligeiro esto podesse saber, e esta amizade fosse descuberta e nom se perdesse antre aqueles que a deviam haver." (Mattoso 1980, p. 56).

${ }^{39}$ Martin 1994.

${ }^{40}$ Véase Dias 2003, Parte I, epígrafe 4. Los manuscritos portugueses de la segunda redacción de la Crónica de 1344 son mayoritariamente del siglo XV y del XVII -"Como atrás disse, há cinco manuscritos portugueses da segunda redacção: quatro completos e um fragmentário. Dois dos códices completos são do século XV: L e P; dois do século XVII: Li, Ev. O fragmento C é do século XV." (Cintra 1951, vol. I, p. CDXCIII)-. En especial, el manuscrito completo de base de la edición de Cintra, el ms. de la Biblioteca de la Academia de las Ciencias de Lisboa (L), que fue de la cámara del rey D. Duarte y de la biblioteca real, será de las primeras décadas del siglo XV (Cintra 1951, vol. I, p. CDXCVIII).

${ }^{41}$ Las interpolaciones favorables a los derechos de Blanca y a su defensa por los Lara han sido identificadas por Cintra 1951, pp. CCLVI y ss. Estos pasajes existen solo en la segunda redacción de la Crónica. Catalán y Andrés, en la introducción de su edición parcial del manuscrito de la primera redacción de la Crónica de 1344 (Catalán, Andrés 1970, p. XXVIII), hablan de los dos linajes (el maldito y el bendito) y refieren como característica de la crónica portuguesa la defensa de los derechos de Blanca al trono de Castilla por oposición a los de Berenguela, lo que implica que los derechos de Alfonso de la Cerda venían de su madre, nieta de Blanca, y no del padre. En nota remiten a los caps. DCCLXXX-DCCLXXXI de la segunda redacción. Sobre la cuestión general del enfrentamiento de derechos entre Blanca y Berenguela, y luego entre Sancho IV y los infantes de la Cerda, y las manipulaciones textuales que han tenido lugar para defender un partido u otro (el que incluye la leyenda de la blasfemia y las profecías), véase Craddock 1986. Martin señala también el eco portugués de los argumentos franceses (Martin 1994, pp. 171-172) en favor de los derechos de los infantes de la Cerda esgrimidos por los de
} 
Pero en el final del siglo XIV, el rey con el cual Portugal estaba esgrimiendo su autonomía era Juan I de Castilla que, según la leyenda, pertenecería ya a la línea bendita, pero que desde el punto de vista portugués no sería muy venerable $^{42}$. En este sentido, la integración de los pasajes favorables a los derechos de Blanca podrían justificarse considerando que se trata de cuestiones más lejanas en el tiempo, mientras que una maldición que favorecía tan declaradamente el padre de Juan I y su linaje podría plantear muchas dudas.

Por lo que se refiere a las características textuales del pasaje existente en la segunda redacción de la Crónica de 1344, hay que subrayar en el texto portugués algunas particularidades bastante compatibles con otros extractos propios de esta versión de finales del siglo XIV, que parece ser marcada por una doble impronta: por un lado, preocupaciones morales y religiosas y, por otro lado, el gusto por la literatura de tipo cortés.

La versión portuguesa de la leyenda es un texto con una evidente calidad compositiva, patente en el dramatismo e intensidad que establece, sobre todo la expectativa que se crea hasta que tomamos conocimiento de en qué consiste la blasfemia del rey Sabio. También podemos señalar el equilibrio de las acciones de Alfonso, que se dirigen contra los hombres y contra Dios, para después ser alertado primero por un caballero y luego por un hombre de religión.

Por lo que se refiere a los trazos de cultura religiosa es fundamental el significado evidente de la leyenda: el tema de la soberbia castigada ${ }^{43}$. En el contexto del incremento de las preocupaciones morales de la segunda redacción de la Crónica de 1344, esta dimensión de la leyenda podría haber sido una razón de peso como para motivar bien su inclusión, bien su desarrollo. Otro dato significativo que nos señala la presencia de una cultura religiosa es

Lara y por los reyes de Francia y que la Crónica de 1344 transmite, con especial énfasis en los derechos de Blanca, mujer de Luis VIII de Francia y madre de Louis IX, al trono de Castilla, por ser mayor que Berenguela, madre de Fernando III (pp. 171-172).

${ }^{42}$ Sobre las estrategias de legitimación y de deslegitimación de los monarcas castellanos, desde Sancho IV hasta Juan I, el que incluye el uso político y la flexibilidad de las leyendas sobre el linaje maldito de Alfonso X en distintas construcciones ideológicas, véase el artículo de Arias 2012. En este estudio queda claro como la leyenda de la blasfemia estaba presente en tiempos de Juan I. Todavía sobre la integración del pensamiento político de don Juan Manuel (lo que incluye la teoría del linaje maldecido frente a la línea bendecida) en la ideología promovida por la dinastía Trastámara, véase Gómez 2002, y sobre todo su alusión a la Arenga de Juan I (p. 171).

${ }^{43}$ La soberbia ha sido una característica criticada desde siempre en la cultura judaico-cristiana, especialmente cuando se presenta en un gobernante. Hemos estudiado este tema, poniendo en relación las leyendas sobre Alfonso X y la tan negativa soberbia en Dias 2003, pp. 350-356. Para un ejemplo de crítica a esta característica en un autor contemporáneo de la segunda redacción de la Crónica de 1344 podemos recordar a Eiximenis, que la condena, no solo en su obra de carácter más civil (véase el Dotzè del Crestià, cap. 611), sino también en textos específicamente religiosos - caso del Llibre dels àngels, cap. XXVIIII del cuarto tratado- agradezco a Isabel Beceiro el haberme sugerido este libro, además de su lectura atenta de estas páginas. 
el hecho de que Alfonso X repita tres veces su blasfemia antes de arrepentirse, o sea, tantas como san Pedro había negado a Cristo.

Por otro lado, hay que tener en cuenta la tonalidad novelesca, compatible con lo que se verifica en otros pasajes propios de la segunda redacción de la Crónica de 1344, como la historia de Hércules ${ }^{44}$. La encontramos en las profecías de la mujer griega, que nos hace recordar los topoi de las novelas bizantinas, y sobre todo en la escena en que la reina llora a causa de sus preocupaciones y el rey insiste para que le cuente la razón de sus lágrimas, y que nos hace recordar el pasaje de los lamentos de Enide en la novela Erec et Enide de Chrétien de Troyes.

Considerando ahora el panorama general de los testimonios de la leyenda, no podemos dejar de recordar y de subrayar la distancia compositiva que existe entre el antecedente textual que hemos identificado y el testimonio portugués. Si aceptamos que este texto sería de 1344, de hecho habría que admitir la existencia de una tradición oral en la cual se habría formado el relato. Ni la memoria del suceso del rayo y su interpretación, referidos por Juan Gil de Zamora, ni los rumores sobre maldiciones, de los que nos habla don Juan Manuel en el Libro de las Armas, a finales de los años 30 del siglo XIV (13371342), podrían dar origen directo a un texto tan elaborado como es el testimonio portugués de la leyenda de la blasfemia. Pero si consideramos que el texto existente en la segunda redacción de la crónica portuguesa es un añadido, una invención de esa obra o, con mayor probabilidad, el desarrollo de algún texto existente en la historia de don Pedro Afonso, quizás puedan ajustarse de modo más lógico las piezas de este puzzle.

Que una versión de la leyenda de la blasfemia del rey Sabio existiera en la primera redacción de la Crónica de 1344 es una posibilidad verosímil. El autor tuvo ocasión de conocer alguna leyenda que existiera y hay detalles textuales compatibles con su línea de pensamiento (como es el caso de las quejas sobre los dineros quitados, que hemos señalado). De confirmarse este postulado, don Pedro Afonso tendría el mérito de haber sido el primero en integrar este episodio en la historiografía, como ha sugerido Craddock ${ }^{45}$. Pero todavía hay que admitir la posibilidad de que la versión existente en el relato de 1344 fuera distinta del texto tan elaborado que existe en la segunda redacción de esta crónica. Probablemente un texto más sencillo, quizás menos agresivo hacia Alfonso X y más compatible con los apuntes existentes en la obra de don Juan Manuel ${ }^{46}$.

\footnotetext{
${ }^{44}$ Que hemos estudiado en Dias 1998 y en 2003, II parte.

${ }^{45}$ Craddock 1986, p. 207.

${ }^{46}$ Señalamos aquí la interesante hipótesis formulada por Lomax 1976, p. 330, quien sugiere la posibilidad de que una versión de la leyenda de la blasfemia de Alfonso X podría haber exis- 
La hipótesis que estamos planteando implica también la valorización de la línea de la difusión clerical de la leyenda como visión. La dimensión religiosa de estos textos no impide presentar también fuertes conexiones con el género historiográfico -Bohigas ${ }^{47}$, habla de una "visión", pero Lomax ${ }^{48}$, considerando el texto más amplio, utiliza el término "crónica", y González Jiménez ${ }^{49}$, habla de "anales"-. Este texto habría tenido algún éxito pues se conserva en varios manuscritos, identificados sobre todo por Pere Bohigas y por Derek Lomax ${ }^{50}$, además de su presencia en el Baladro del Sabio Merlín. Algunos de estos manuscritos se relacionan con el monasterio de Santo Domingo de Silos, donde han sido también identificados milagros que se refieren al rey Alfonso el Sabio ${ }^{51}$.

El estilo de la Visión es bastante más sencillo que el relato que se encuentra en la segunda versión de la Crónica de 1344. La Visión es también más positiva hacia Alfonso X, como Funes ${ }^{52}$ ha subrayado. El relato incluye la idea de la alianza del rey con Dios y santa María, quien intercede por él, permitiendo que su alma vaya al Purgatorio a pesar de la blasfemia. Convergen

tido en la Crónica cumplida, una obra de don Juan Manuel ahora perdida. Según este autor, un ejemplar de esta crónica podría haber llegado al monasterio de Silos, donde habría servido de inspiración al monje que escribió la crónica y la visión que vamos a considerar enseguida. Esta hipótesis es considerada verosímil por González 1995, pp. 470-471, quien se interroga sobre el papel que don Juan Manuel hubiera podido desarrollar con relación al relato de la blasfemia.

${ }^{47}$ Bohigas 1941.

${ }^{48}$ Lomax 1976.

${ }^{49}$ González 1995.

${ }^{50}$ Bohigas ha identificado dos manuscritos: el ms. 431 de la Biblioteca Nacional de Madrid y el ms. 276 de la Biblioteca de Cataluña, y los ha editado (Bohigas 1941, pp. 384 y 390-393 -ed. del ms. 431-; Bohigas 1935, pp. 264-266 -ed. del ms. 276-). Suárez 1942-1943, también estudia el ms. 431 pero edita solo la colección de hazañas allí existente. Lomax 1976, refiere el ms. 431 y tres otros mss. que integran la visión en textos más amplios de carácter cronístico y edita esta versión más desarrollada existente en los tres manuscritos (pp. 331-337), que son más tardíos que el ms. 431 -que es del siglo XIV (p. 327)-. Uno de los manuscritos de la Biblioteca Nacional de España, del siglo XV, ya fue identificado y editado por Ruiz de Obregón 1915, pp. 438-440 -lo curioso de este artículo es que su autor desconoce la versión portuguesa de la blasfemia y por eso su estudio solo considera la Visión y las versiones más tardías de la leyenda-. Otra edición es la de González 1995, pp. 475-486, basada en el ms. O-15 de la Biblioteca de la Real Academia de la Historia (de la primera mitad del siglo XVI), quien presenta también una propuesta de historia de la formación de las distintas partes del texto (pp. 462-464 y 473-474).

${ }^{51}$ Lomax considera que la crónica que edita es especialmente favorable a la abadía de Silos (Lomax 1976, p. 326). Lo mismo defiende González 1995, pp. 471-473. El texto presenta al inicio la noticia de un milagro en que santo Domingo se aparecía a Alfonso X. Sobre la presencia (positiva) de Alfonso X en milagros compuestos en Silos, véase Arizaleta 2004, p. 90n, que refiere el milagro (uno de los compuestos en Silos por Pero Marín en 1284-1285) que sería fuente de un pasaje existente en la crónica publicada por Lomax 1976, pp. 325-326. El tema de los milagros de Pero Marín que se refieren al rey Sabio lo desarrolla Arizaleta en un artículo posterior (Arizaleta 2009). Aún sobre esta crónica de Silos, véase Funes 1994, pp. 70 y ss.

${ }^{52}$ Funes 1994, p. 77. 
aquí los temas de una visión de Alfonso X (que, como cualquier visión, ocurre en un ambiente de gran claridad: $v n$ resplandor de claridat, que parescia seer resplandor commo de fuego ${ }^{53}$; luego, no muy lejos de la idea de un rayo); la crítica de la divinidad al soberano por su blasfemia (pero no demasiado severa); la toma de conocimiento de la ira divina por el hermano del rey, el infante Manuel; la maldición a Sancho IV y su extensión hasta la cuarta generación y, por fin, la penitencia del rey Sabio, que prepara el momento de su muerte.

El texto de esta Visión, que será de la segunda mitad del siglo XIV ${ }^{54}$, está marcado por un claro entorno clerical y también refleja la propaganda antipedrista típica del contexto de las guerras entre Pedro I y Enrique II de Trastámara (anterior al periodo de la crisis sucesoria portuguesa). Este contexto sería especialmente favorable al enlace de piezas anteriormente sueltas (como es el caso de los relatos de postura pro-sanchista que anteceden la visión, como señala González Jiménez ${ }^{55}$ ), de modo que formasen una leyenda políticamente útil. El uso de la leyenda en el contexto de un suceso tan serio como las guerras que han antecedido el inicio de la dinastía Trastámara puede haber sido el motor que estimuló su difusión por toda la península, pues enseguida, y por los mismos años, tenemos el testimonio de la segunda redacción de la Crónica de 1344 y las referencias existentes en el Terç del Crestià, de Francesc Eiximenis; en la Crónica d'Espayña de García de Eugui y la versión de la Crònica de Pere $I I I^{56}$; y luego los muchos otros textos, con tintes proféticos, que ya han sido señalados y estudiados por la crítica ${ }^{57}$.

${ }^{53}$ Bohigas 1941, p. 390.

${ }^{54}$ Lomax 1976, p. 327.

${ }^{55}$ González 1995, pp. 463 y 479-480.

${ }^{56} \mathrm{El} \mathrm{Terç} \mathrm{del} \mathrm{Crestià} \mathrm{fue} \mathrm{redactado} \mathrm{a} \mathrm{lo} \mathrm{largo} \mathrm{de} \mathrm{1384,} \mathrm{pero} \mathrm{utilizando} \mathrm{materiales} \mathrm{elaborados}$ anteriormente, en los primeros años de la década de los 80 . Sobre el largo y complejo proceso de composición del Crestià, véase Renedo 2013 -agradezco al autor haberme facilitado una copia de su artículo-. Se trata, pues, de una obra que sería contemporánea de la segunda redacción de la Crónica de 1344. Funes 1994,p. 91 refiere y comenta estas alusiones. Más recientemente, las alusiones de Eiximenis a la leyenda de la blasfemia de Alfonso X han sido comentadas por Renedo 2010. Para una visión general sobre la profecía en Eximenis, véase Bohigas 1982. La Crónica d'Espayña de García de Eugui, también de finales del siglo XIV, integra una alusión a la leyenda de la blasfemia publicada por González 1995, p. 487 y por Funes 1994, pp. 94-96. La Crònica de Pere III, también de los años 80 del siglo XIV, atribuye la blasfemia a Fernando IV -el pasaje es editado por Funes 1994, pp. 92-93 y por González 1995, p. 486-.

${ }^{57}$ Especialmente El Baladro del Sabio Merlín, pero también en otros textos. Catalán 1953, pp. 63-70 comenta las profecías existentes en el Poema de Rodrigo Yáñez. Ballesteros-Beretta 1963, p. 210 habla de Rodrigo Sánchez de Arévalo, História Hispánica (Roma, 1496), Diego Rodríguez de Almela, Valerio de las Historias (Murcia, 1487), Fray Alonso de la Espina, Fortaleza de la Fe, Zurita, Colmenares y otros. Funes 1994, p. 90 ss. presenta y estudia varios de estos textos. González 1995, p. 464 refiere García de Euguí, la Crònica de Pere III, Alonso de Espina, Rodrigo Sánchez de Arévalo y Diego Rodríguez de Almela y contrasta las distintas versiones de la leyenda. Estas versiones posteriores de la leyenda ya habían sido identificadas y cotejadas por Ruiz de Obregón 1915. 
La hipótesis que acabamos de plantear -atribuir al pasaje existente en la segunda redacción de la Crónica de 1344 la fecha de esta obra- parece racionalizar el panorama general de la evolución del relato de la leyenda de la blasfemia del rey Sabio, pues no es muy lógico que apareciera un texto tan elaborado en un lugar donde su pertinencia es muy relativa, mientras que no existiera -por los mismos años o poco antes- un registro de esta historia en Castilla, donde su valor pragmático es evidente.

Podemos así pensar en un primer momento dónde se verificó simplemente la narración de algún suceso, seguido de su interpretación en términos favorables a Alfonso X, por Juan Gil de Zamora. Solo en un segundo momento distintas piezas se habrían reunido para dar origen a los relatos que conocemos. Mientras tanto, por cierto, han podido existir variantes que se habrían divulgado como historia de familia (fuera de los Manuel, de los Lara, o de ambos), y que don Pedro Afonso de Barcelos hubiera conocido y eventualmente reproducido. Pero todo indica que el gran momento de la irrupción de la leyenda fue el contexto político e ideológico de los enfrentamientos entre Pedro I y Enrique II. A partir de entonces, el relato ha tenido el éxito que se conoce.

Queda por revisar en detalle la cuestión de la relación de la Visión con la leyenda de la blasfemia. El tono favorable a Alfonso X de algunas partes de la Visión, al que se puede sumar su mayor sencillez estilística, puede hacernos pensar que este texto, en su origen, podría ser anterior a la leyenda, y haber sido, en un segundo momento, contaminado por los intereses inherentes a la crisis sucesoria castellana. En este caso, podría ser el eslabón perdido (o seudo perdido) de conexión entre los textos más antiguos y la leyenda. Pero también no podemos descartar otras posibilidades, alternativas o simultáneas. Quizás la Visión pudo haber sido una respuesta a una leyenda oral, intentando ofrecer un final más positivo a una historia corriente. Luego puede tratarse de dos líneas textuales independientes, paralelas (una de carácter más clerical, otra más aristocrático), o de dos líneas que en distintas ocasiones se hayan influenciado mutuamente. Pensamos que este es un problema que carece un estudio atento que tenga en cuenta todos los testimonios existentes de la Visión y de la leyenda. Se trata, pues, de un tema que está lejos de quedar agotado.

\section{BIBLIOGRAFÍA CITADA}

Arias Guillén, Fernando (2012), El linaje maldito de Alfonso X. Conflictos en torno a la legitimidad regia en Castilla (c. 1275-1390), "Vínculos de Historia" 1, pp. 147-163.

Arizaleta, Amaia (2004), De la soberbia del rey: dos formas breves en la construcción historiográfica, en Cacho Blecua, Juan Manuel; Lacarra, 
María Jesús (eds.), Tipología de las formas narrativas breves románicas medievales-III, Zaragoza, Universidad de Zaragoza - Granada, Universidad de Granada, pp. 79-110.

Arizaleta, Amaia (2009), La memoria del monarca: Alfonso X, testigo de Pero Marín (Miraculos romançados, 4), "Cahiers d'Études Hispaniques Médiévales" 32, pp. 267-300.

Ballesteros-Beretta, Antonio (1963), Alfonso X el Sabio, Madrid - Barcelona, Salvat.

Bautista, Francisco (2009), Breve historiografía: listas regias y anales en la Península Ibérica (siglos VII-XII), "Talia Dixit" 4, pp. 113-190. Disponible en: http://www.eweb.unex.es/eweb/arengas/td4Bautista.pdf [consulta: $16 / 08 / 2013]$.

Berganza, Fr. Francisco de (ed.) (1721), Memorias antiguas de Cardeña en Antiguedades de España, propugnadas en las noticias de sus reyes, en la coronica del real monasterio de San Pedro de Cardeña, en historias, cronicones, y otros instrumentos manuscritos, que hasta aora no han visto la luz publica, Madrid, Francisco del Hierro, Parte II, pp. 588-590.

Bohigas, Pere (1935), Profecies de Merlí. Altres profecies contingudes en manuscrits catalans, "Butlletí de la Biblioteca de Catalunya" 8, pp. 253-279.

Bohigas, Pedro (1941), La visión de Alfonso X y las Profecías de Merlín, "Revista de Filología Española" 25, pp. 383-398.

Bohigas, Pere (1982), Prediccions i profecies en les obres de Fra. Francesc Eiximenis, en Bohigas, Pere, Aportació a l'Estudi de la Literatura Catalana, Montserrat, Publicacions de l'Abadia de Montserrat, pp. 94-115.

Catalán, Diego (1953), Poema de Alfonso XI. Fuentes, dialecto, estilo, Madrid, Gredos.

Catalán, Diego; Andrés, María Soledad de (eds.) (1970), I Edición crítica del texto español de la Crónica de 1344 que ordenó el conde de Barcelos don Pedro Alfonso, Madrid, Gredos.

Cintra, Luís Filipe Lindley (estudio y ed.) (1951-1990), Crónica Geral de Espanha de 1344, Lisboa, IN-CM.

Craddock, Jerry R. (1986), Dynasty in Dispute: Alfonso X el Sabio and the Succession to the Throne of Castile and Leon in History and Legend, "Viator" 17, pp. 197-219.

Dias, Isabel de Barros (1998), Le Duel des Géants, en Brusegan, Rosanna; Zironi, Alessandro; Berthelot, Anne; Buschinger, Danielle (eds.), L'Antichitánella cultura europea del Medioevo, Greifswald, Reineke, pp. 195-205. 
Dias, Isabel de Barros (2003), Metamorfoses de Babel. A Historiografia Ibérica (sécs. XIII-XIV): Construções e Estratégias Textuais, Lisboa, Fundação Calouste Gulbenkian - Fundação para a Ciência e Tecnologia - Ministério da Ciência e do Ensino Superior.

Dias, Isabel de Barros (2012), A blasfémia do Rei Sábio: os antecedentes da lenda, en Martínez Pérez, Antonia; Baquero Escuedro, Ana Luisa (eds.), Estudios de Literatura Medieval. 25 años de la AHLM, Murcia, EDITUM, pp. 189-196.

Eiximenis, Francesc (1494), Llibre dels àngels impreso por Johan Rosenbach de Haydelberch, Barcelona. Reproducción digital disponible en la Biblioteca Virtual Miguel de Cervantes - Joan Lluís Vives: http://www. lluisvives.com/servlet/SirveObras/24672785545034386754491/index.htm [consulta: 16/08/2013].

Eiximenis, Francesc (1986), Dotzè llibre del Crestià, eds. Curt Wittlin, Arseni Pacheco, Jill Webster, Josep Maria Pujol, Josefina Fíguls, Bernat Joan, August Bover, Gerona, Col·legi Universitari de Girona - Diputació de Girona, vol. II-1.

Entwistle, William J. (1925), The Arthurian Legend in the Literatures of the Spanish Peninsula, Londres - Toronto - Nueva York, J.M. Dent \& Sons, Ltd. - E. P. Dutton \& Co.

Fita, Fidel (ed.) (1884), Biografias de San Fernando y de Alfonso el Sabio por Gil de Zamora, "Boletín de la Real Academia de la Historia" 5, pp. 308-328. Transcripción disponible en Cervantes virtual: http://bib. cervantesvirtual.com/servlet/SirveObras/1250498645670 4839654657/p0000031.htm\#I_44_ [consulta: 20/11/2012].

Flórez, Enrique (ed.) (1799), Chronicon de Cardeña, "España Sagrada" 23, pp. 371-377.

Funes, Leonardo (1993), La blasfemia del rey Sabio: itinerario narrativo de una leyenda (Primera parte), "Incipit" 13, pp. 51-70.

Funes, Leonardo (1994), La blasfemia del rey Sabio: itinerario narrativo de una leyenda (Segunda parte), "Incipit" 14, pp. 69-101.

Gómez Redondo, Fernando (2002), Don Juan Manuel, Trastámara, "Cahiers de Linguistique et de Civilisation Hispaniques Médiévales”25,pp. 163-181.

González Jiménez, Manuel (1995), Unos anales del reinado de Alfonso X,

"Boletín de la Real Academia de la Historia" 192/3, pp. 461-491.

González Jiménez, Manuel (2004), Alfonso X el Sabio, Barcelona, Ariel.

Juan Manuel (1983), Crónica Abreviada, en Blecua, José Manuel (ed.), Obras Completas de don Juan Manuel, Madrid, Gredos, vol. II, pp. 507-815.

Juan Manuel (2005), Libro de las Armas. Transcripción del ms. 6376 de la BNE (ff. 25r-31v), ed. José Luis Villacañas Berlanga, para la 
Biblioteca Saavedra Fajardo, Murcia, disponible en: http://saavedrafajardo.um.es/WEB/archivos/LIBROS/Libro0167.pdf [consulta: 20/11/2012]

Linehan, Peter (1993), History and Historians of Medieval Spain, Oxford, Oxford University Press.

Lomax, Derek W. (1976), Una crónica inédita de Silos, en Homenaje a Fray Justo Pérez de Urbel OSB, Silos, Abadía de Silos, vol. 1, pp. 323-337.

Martin, Georges (1994), Alphonse X maudit son fils, “Atalaya" 5 ( = L'invective au Moyen Âge), pp. 151-179.

Mattoso, José (ed.) (1980), Livro de Linhagens do Conde D. Pedro, Lisboa, Academia das Ciências (Portugaliae Monumenta Historica. Nova Série; 1$)$.

Mattoso, José (1992), As Três Faces de Afonso Henriques, "Penélope" 8, pp. 25-42.

Menéndez Pidal, Ramón (1918), El códice de San Pedro de Cardeña "Boletín de la Real Academia de la Historia" 72, pp. 188-193.

Ramos Nogales, Rafael (1992), Notas al Libro de las Armas, "Anuario Medieval" 4, pp. 179-192.

Renedo, Xavier (2010), Eiximenis y Castilla (reyes, profecías y política), en Fradejas Rueda, José Manuel; Dietrick Smithbauer, Déborah; Martín Sanz, Demetrio; Díez Garretas, $\mathrm{M}^{\mathrm{a}}$ Jesús, Actas del XIII Congreso Internacional. Asociación Hispánica de Literatura Medieval. In Memoriam Alan Deyermond, Valladolid, Ayuntamiento de Valladolid Universidad de Valladolid, pp. 183-216.

Renedo, Xavier (2013), Notes sobre la datació del Primer, el Segon $i$ el Terç del Crestià de Francesc Eiximenis, dins Miscel-lània Albert Hauf 5. Estudis de Llengua i Literatura Catalanes 66, Barcelona, Publicacions de l'Abadia de Montserrat, pp. 5-33.

Ruiz, María Cecilia (1989), Literatura y política: el Libro de los Estados y el Libro de las Armas de don Juan Manuel, Potomac (Maryland), Scripta Humanistica.

Ruiz de Obregón Retortillo, Juan (1915), Alfonso X el emplazado, "Revista de Archivos, Bibliotecas y Museos" 32, pp. 420-449.

Suárez Verdaguer, Federico (1942-1943), La coleccion de fazañas del ms. 431 de la Biblioteca Nacional, "Anuario de Historia del Derecho Español" 14, pp. 579-591.

Fecha de recepción del artículo: enero 2013

Fecha de aceptación y versión final: septiembre 2013 